\title{
Retro-Viral Disease Status of Patients on D0TS Tuberculosis Treatment Strategy in a South-East Nigeria Teaching Hospital
}

\section{Chinedu A. Idoko ${ }^{1}$, Chinyere Okeke1, Chinelo I. Idoko², Obiora Onowu ${ }^{3}$, Ikechukwu Orakwue1, Chuka Obienu ${ }^{1}$}

\author{
${ }^{1}$ Department of Community Medicine, University of Nigeria, Enugu, Nigeria \\ ${ }^{2}$ Department of Business Administration, Enugu State University of Science \& Technology, Enugu, Nigeria \\ ${ }^{3}$ Tricity Health Care, LLC, Tx., USA \\ Email: *chineduarthur@yahoo.com
}

How to cite this paper: Idoko, C.A. Okeke, C., Idoko, C.I., Onowu, O., Orakwue, I. and Obienu, C. (2021) Retro-Viral Disease Status of Patients on DOTS Tuberculosis Treatment Strategy in a South-East Nigeria Teaching Hospital. Health, 13, 839-845.

https://doi.org/10.4236/health.2021.138064

Received: July 12, 2021

Accepted: August 17, 2021

Published: August 20, 2021

Copyright $\odot 2021$ by author(s) and Scientific Research Publishing Inc. This work is licensed under the Creative Commons Attribution International License (CC BY 4.0).

http://creativecommons.org/licenses/by/4.0/

\begin{abstract}
Introduction: Tuberculosis is associated with HIV/AIDS and it has been recognized as one of the most frequent opportunistic infections in persons with HIV. Tuberculosis is the leading cause of death in people with HIV having an adverse effect on HIV progression. Objectives: The objective is to determine the retroviral disease status of patients on the DOTS strategy. Materials and Methods: A retrospective study of patients was seen at the University of Nigeria Teaching Hospital from January 2013 to April 2015. Relevant information was collected from patients' folders. Statistical analysis was done with the SPSS and results were represented in tables. Results: 171 patients (77\%) were HIV negative while 51 (23\%) were positive giving an HIV negative/HIV positive ratio of 3.35:1. 97 patients (43.7\%) had 6 months duration of treatment. The least was 2 patients $(0.9 \%)$ that complied with their medication for 7 months. The $61-70$ years age group accounted for the least number of HIV-positive patients. Conclusion/Recommendations: There is strong tuberculosis/HIV co-infectivity among the studied population. Strategies to reduce the burden of TB/HIV co-infection should be strengthened.
\end{abstract}

\section{Keywords}

Retroviral Status, Patients, DOTS, Tuberculosis, South-East Nigeria

\section{Introduction}

Tuberculosis, an infectious airborne disease affects all countries with $85 \%$ of cases occurring in Africa and Asia. Globally there are 22 High Burden Countries 
(HBC) that account for $80 \%$ of the world's TB cases. Nigeria ranks 10 th among these $22 \mathrm{HBC}$ around the world and 4th in Africa [1].

Tuberculosis is associated with HIV/AIDS and it has been recognized as one of the most frequent opportunistic infections in persons with HIV due to compromised immunity of such persons [2] [3]. The recurrent epidemic of HIV in many African countries has increased the burden of tuberculosis many folds. Tuberculosis is the leading cause of death in people with HIV and also has an adverse effect on HIV progression. HIV infection has been identified as the highest risk factor that triggers the reactivation of latent infection with TB [1]. It is always of best practice to rule out HIV in patients with active tuberculosis. This would assist the health care provider in the management of the disease, especially considering antiretroviral therapy.

WHO adopted the Directly Observed Treatment Short course (DOTS) strategy in 1990 with Nigeria taking clue in the year 1993. Despite this, Tuberculosis has not been effectively controlled. It becomes even more difficult with Tuberculosis/HIV co-infectivity [3] [4]. The idea behind DOTS is that the affected patient takes his anti-tuberculin drugs under the strict supervision of a trained observer especially in the intensive phase of the treatment. This could be achieved either by the patient going to the clinic to take the drugs or an observer going to the patients house. This is done in order to reduce and prevent relapse as well as issues of multi-drug-resistant tuberculosis. The introduction of DOTS since 1990 has seen a $47 \%$ drop in the death rate of TB patients [5] showing that the strategy is effective globally.

This study, therefore, was conducted to determine the retroviral status of patients on DOTS tuberculosis treatment at the Chest Clinic UNTH from 2013-2015. Patients with both HIV and TB are at least 10 times more likely to develop active TB than someone without HIV [4].

\section{Study Objectives}

The General Objective was to determine the retroviral disease status of patients on DOTS Tuberculosis Treatment in Nigeria using chest clinic old UNTH as a case study while the specific objectives were to determine the effectiveness and success rates of DOTS TB, to find out the duration of treatment of the patients and to find out the relationship between Age and Retroviral Disease status of patients on the treatment.

\section{Materials and Methods}

\subsection{Study Area}

The study was conducted at the chest clinic of University of Nigeria Teaching Hospital, Enugu. Enugu is the capital of Enugu state and has an estimated population of 3.8 million [6] [7].

The Chest Clinic, run by the Community Medicine Department UNTH runs every Monday, Wednesday, and Friday with an average attendance of 15 - 20 pa- 
tients per week.

\subsection{Study Design}

The study was a retrospective study of patients that were seen at the UNTH chest clinic from January 2013 to April 2015. Patients' folders were retrieved from the medical records and relevant information obtained for the study.

\subsection{Study Population}

The study population was patients (both male and female) that attended the chest clinic of UNTH within the stated period.

\subsection{Sample Size Determination}

Based on a previous and related study, the sample size was derived using the formula

$$
N=Z^{2} P(1-P) / D^{2}
$$

where $N$ is the normal/sample size for the study,

$P=64 \%$ (compliance rate in Nepal by Shiyalap 2013) [8].

$Z=1.96$ at $95 \%$ confidence limit.

$D$ (sampling error $)=5 \%(0.05)$ which is the tolerance error or margin of error tolerated.

$$
\begin{aligned}
N & =1.96 \times 0.64 \times(1-0.64) / 0.05^{2} \\
& =1.2544 \times 0.36 / 0.0025 \\
& =180.4 \\
& =180(\text { minimum sample size })
\end{aligned}
$$

This comes to 200 after accommodating for attrition and approximating. Sample size used in this study is 222 patients.

\subsection{Statistical Analysis}

Statistical analysis was done with the statistical Package for the Social Sciences (SPSS) and results presented in tables.

\section{Results}

Table 1 shows that patients' ages ranged from 2 years to 85 years with a mean age of 38 years. The 21 - 30 years age group was the most commonly represented with 71 patients $(32 \%)$ and the $>80$ years groups were the least represented with 2 patients $(0.9 \%)$.

Table 2 reflects that 171 patients (77\%) were HIV negative while 51 (23\%) were HIV positive giving an HIV negative versus HIV positive ratio of 3.35:1.

In Table 3, here the duration of treatment also varied among patients, with 97 patients $(43.7 \%)$ taking their treatment up to 6 months. The least was 2 most patients $(0.9 \%)$ that complied with their medication for 7 months. 
Table 1. Social demographic characteristics of studied populations.

\begin{tabular}{ccccccccc}
\hline \multirow{2}{*}{$\begin{array}{c}\text { Age } \\
\text { (years) }\end{array}$} & Frequency & \multicolumn{2}{c}{ Sex } & \multicolumn{3}{c}{ Marital status } & \multicolumn{2}{c}{ Formal Education } \\
\cline { 2 - 9 } & Male & Female & Single & Married & Widowed & Yes & No \\
\hline $1-10$ & 6 & 2 & 4 & 6 & & & 2 & \\
$11-20$ & 23 & 9 & 14 & 22 & 1 & & 9 & \\
$21-30$ & 71 & 28 & 43 & 52 & 18 & 1 & 28 & \\
$31-40$ & 49 & 34 & 15 & 23 & 26 & & 35 & \\
$41-50$ & 36 & 24 & 12 & 3 & 34 & & 25 & \\
$51-60$ & 21 & 13 & 8 & 2 & 18 & 1 & 13 & \\
$61-70$ & 11 & 7 & 4 & 2 & 9 & & 6 & 1 \\
$71-80$ & 3 & 1 & 2 & 1 & 2 & & & 1 \\
$>80$ & 2 & 1 & 1 & 1 & & 1 & & 1 \\
Total & 222 & 119 & 103 & 112 & 107 & 3 & 118 & 3 \\
\hline
\end{tabular}

Table 2. Retroviral disease status of patients using dots TB.

\begin{tabular}{cccc}
\hline RVD Status & Frequency & Percentage & Ratio \\
\hline Negative & 171 & 77 & 3.15 \\
Positive & 51 & 23 & 1 \\
Total & 222 & 100.0 & \\
\hline
\end{tabular}

Table 3. Duration of treatment of patients using dots TB.

\begin{tabular}{ccc}
\hline Duration of treatment & Frequency & Percentage \\
\hline 1 mth and less & 47 & 21.7 \\
2 mths & 25 & 11.3 \\
$3 \mathrm{mths}$ & 12 & 5.4 \\
$4 \mathrm{mths}$ & 16 & 7.2 \\
$5 \mathrm{mths}$ & 16 & 7.2 \\
$6 \mathrm{mths}$ & 97 & 43.7 \\
$7 \mathrm{mths}$ & 2 & 0.9 \\
$8 \mathrm{mths}$ & 4 & 1.8 \\
$12 \mathrm{mths}$ & 3 & 1.4 \\
Total & 222 & 100 \\
\hline
\end{tabular}

Table 4 is on the outcome of treatment where 92 patients $(41.4 \%)$ were successfully treated and discharged home with 7 patients $(3.2 \%)$ patients referred to other centres. Interestingly 11 patients $(4.9 \%)$ completed their treatments though did not show up for discharge while another 3 (1.4\%) had a relapse. Furthermore, 89 patients $(40.1 \%)$ received treatment with unknown outcome and 17 patients (7.7\%) unfortunately died; 3 (1.4\%) patients were still on treatment.

In Table 5, it is found that $51(23 \%)$ of the 222 patients were HIV positive 
Table 4. Outcome of treatment of patients using dots TB.

\begin{tabular}{ccc}
\hline Outcome of treatment & Frequency & Percentage \\
\hline Referred & 7 & 3.2 \\
Discharged & 92 & 41.4 \\
Didn't show up for discharge & 11 & 4.9 \\
Still on treatment & 3 & 1.4 \\
Dead & 17 & 7.7 \\
Unknown & 89 & 40.1 \\
Relapse & 3 & 1.4 \\
Total & 222 & 100.0 \\
\hline
\end{tabular}

Table 5. Relationship between age and RVD status of patients using dots TB.

\begin{tabular}{cccc}
\hline $\begin{array}{c}\text { Age } \\
\text { (years) }\end{array}$ & Negative & Positive & Total \\
\cline { 2 - 4 } $1-10$ & 1 & 5 & 6 \\
$11-20$ & 20 & 3 & 23 \\
$21-30$ & 59 & 12 & 71 \\
$31-40$ & 34 & 15 & 49 \\
$41-50$ & 16 & 20 & 36 \\
$51-60$ & 16 & 5 & 21 \\
$61-70$ & 10 & 1 & 11 \\
$71-80$ & 3 & 0 & 3 \\
$>80$ & 2 & 0 & 2 \\
Total & 171 & 51 & 222 \\
\hline
\end{tabular}

RVD: Retroviral disease.

with 20 patients (39.2\%) belonging to the $41-50$ years age group. The $61-70$ years age group accounted for the least number of HIV patients.

\section{Discussion}

Tuberculosis control programs currently emphasize the DOTS Strategy, promoted by World Health Organization (WHO) and the International Union against Tuberculosis and Lung Disease (IUATLD) [9] [10].

This study involved the review of 222 folders of patients, out of which 119 (53.6\%) were males and 103 (46.3\%) female. 92 patients (41.2\%) seen in the period of the study were successfully treated and discharged as cured.

107 patients were non-compliant to treatment and 17 (7.7\%) of these died, who were HIV positive patients. This is consistent with the findings of Amoran et al. who noted that the HIV-positive patients that were non-complaint with medications also died in his study in Ogun State, Nigeria [11]. 
Most of the patients were HIV negative 171 (77\%) while 51 (23\%) were HIV positive which is also almost consistent with the findings of Amoran et al., who noted $73.9 \%$ (HIV negative) and $26.1 \%$ (HIV positive) in a study done in Ogun State [11]. This indeed reflects a strong association between tuberculosis and HIV infection. In this study, there was no assessment of the extent of immunosuppression among HIV-positive patients. Tuberculosis patients with HIV disease though however may not have been recognized as such have a number of intense sequelae including but not limited to delayed diagnosis, delays in treatment and faster progression to untreatable Tuberculosis [12]. It is worthy of note that symptoms that Tuberculosis patients with HIV co-infectivity presents do not usually follow the stereotyped fashion of cough for more than three weeks, etc. [13]. Culture of mycobacteria remains the gold standard for diagnosis of tuberculosis and is now routinely recommended to assist tuberculosis diagnosis in HIV patients, though more cumbersome and of course, more expensive [14].

One hundred and seven (41.3\%) of the 222 patients did not complete the duration of their treatment. The default was highest at 2 months; 21 (9.5\%), which is almost consistent with the findings of Amoran et al. who noted a default rate of $12.6 \%$ at the 2 nd month in their study. This could be attributable to ignorance of the weighty consequences of a treatment failure or advent of drug-resistant tuberculosis, difficulty in coping with the side effects of the drugs (especially which may be more pronounced with patient on anti-retroviral medication). The default rate here (41.3\%), however, is not consistent with the findings of Inotu et al. that obtained a default rate of $23.8 \%$ in their study in Benin City, Nigeria [15].

In this study, 17 patients (7.7\%) died while there was relapse in 3 patients (1.4\%). However, it was not expressly captured if these mentioned subsets were HIV positive. This is somewhat similar to a previous study done in Ethiopia where 74 patients $(9.9 \%)$ had unsuccessful treatment outcomes (death and treatment failure) [16].

\section{Conclusions and Recommendations}

The exact cause of death in the studied population could not be ascertained. There is, however, obviously strong tuberculosis and HIV co-infectivity among the studied population.

Strategies to reduce the burden of TB/HIV co-infection should be strengthened, while the two-way referral system should be made stronger for enhanced treatment adherence.

\section{Conflicts of Interest}

The authors declare no conflicts of interest regarding the publication of this paper.

\section{References}

[1] World Health Organization (WHO) (1996) Group at Risk. WHO's Report on the 
Tuberculosis Epidemics. WHO, Geneva.

[2] World Health Organization (WHO) (2008) Global Tuberculosis Control. WHO Report, Geneva.

[3] Okeke, T.A. and Aguwa, E.N. (2006) Evaluation of the Implementation of Directly Observed Treatment Short Course by Private Medical Practitioners in the Management of Tuberculosis in Enugu. Nigeria Tanzania Health Research Bulletin, 8, 86-89.

[4] Okuonghae, D. and Korobeinikov, A. (2007) Dynamics of Tuberculosis: The Effect of Direct Observation Therapy Strategy (DOTS) in Nigeria. Mathematical Modelling of Natural Phenomena, 2, 101-113.

[5] World Health Organization (WHO) (1994) Framework for Effective Tuberculosis Control. WHO, Geneva.

[6] Idoko, C.A., Idoko, C.I. and Chidolue, I.C. (2019) Attitude of Women in a Nigerian Local Government to Reproductive Health Following Health Education Intervention. African Health Sciences, 19, 3018-3026. https://doi.org/10.4314/ahs.v19i4.23

[7] Idoko, C.A., Omotowo, I.B., Agunwa, C.C., Okeke, C., Obi, I.E., Ndu, A.C., Ekwueme, O.C., Uzochukwu, B.S.C. and Onwujekwe, O. (2017) Effect of Health Education on Reproductive Health Knowledge of Women in Two Local Government Areas, South East Nigeria, a Cross-Sectional Study. International Journal of Medicine and Health Development, 22, 130-137.

[8] Dim, C.C., Dim, N.R. and Morkve, O. (2011) Tuberculosis: A Review of Current Concepts and Control Programme in Nigeria. Nigerian Journal of Medicine, 20, 200-206.

[9] Park, K. (2004) Park's Textbook of Preventive and Social Medicine. 18th Edition, M/S Banarsidas Bhanot, Jabalpur, 131-140.

[10] Omotowo, B.I., Itanyi, I., Ndibuaagu, E.O., Agunwa, C.A., Obi, I.E., Idoko, C.A. and Ndu, A.C. (2019) Comparative Study of Six-Month and Eight-Month Treatment of New Smear Positive Tuberculosis Cases at a Tertiary Health Facility in Enugu, South-Eastern Nigeria. International Journal of Medicine and Health Development, 24, 78-84. https://doi.org/10.4103/ijmh.IJMH_24_19

[11] Amoran, O.E., Osiyale, O.O. and Lawal, K.M. (2011) Pattern of Default among Tuberculosis Patients on Directly Observed Therapy in Rural Primary Health Care Centres in Ogun State, Nigeria. Journal of Infectious Diseases and Immunity, 3, 90-95.

[12] Rajasekaran, S., Mahilmaran, A., Annadural, S., Kumar, S. and Raja, K. (2007) Manifestation of Tuberculosis in Patients with Human Immunodeficiency Virus. A Large Indian Study. Annals of Thoracic Medicine, 2, 58-60. https://doi.org/10.4103/1817-1737.32231

[13] Reid, M.J. and Shah, N.S. (2009) Approaches to Tuberculosis Screening and Diagnosis in People with HIV in Resource-Limited Settings. The Lancet Infectious Diseases, 9, 173-184. https://doi.org/10.1016/S1473-3099(09)70043-X

[14] World Health Organization (2010) Improving the Diagnosis and Treatment of Smear-Negative Pulmonary and Extrapulmonary Tuberculosis among Adults and Adolescents. Recommendations for HIV-Prevalent and Resource-Constrained Settings. Geneva.

[15] Inotu, A. and Abebe, F. (2014) Assessment of Defaulting from Directly Observed Treatment Short Course (DOTS) and Its Determinants in Benin City, Nigeria. Journal of Tuberculosis Research, 2, 30-39. https://doi.org/10.4236/jtr.2014.21004

[16] Worku, S., Derbie, A., Mekonen, D. and Biadglegne, F. (2018) Treatment Outcomes of Tuberculosis Patients under DOTS at Debre Tabar General Hospital, North-West Ethiopia: Nine-Year Retrospective Study. Infectious Diseases of Poverty, 7, 16. 